7. Reprod. Fertil. (1960) 1, 7 1 -83

\title{
THE INCIDENCE OF EMBRYONIC MORTALITY AS A CHARACTERISTIC OF THE INDIVIDUAL SOW
}

\author{
J. S. PERRY \\ Agricultural Research Council, Institute of Animal Physiology, \\ Babraham, Cambridge
}

(Received I I th August 1959)

\begin{abstract}
Summary. Embryonic mortality was estimated by comparing the number of piglets born with the number of corpora lutea counted at laparotomy early in pregnancy. It was found that embryonic loss was non-randomly distributed in the first pregnancy in thirty-six animals, and that it was apparently related to the parentage, particularly to the sire, of the pregnant female.

The same estimation was subsequently carried out in two or more successive pregnancies in each of sixteen pedigree Large White sows, selected for this purpose from the progeny of two unrelated males and four females, each male having served two of the females and each female being the dam of four of the experimental animals. The latter were mated alternately with two young males. The half-sister groups differed significantly with regard to the percentage mortality among their embryos; the full-sister groups within them differed, but not significantly, and the mortality was quite independent of the male with which they were mated.

It thus appears that the individual sow is liable to a characteristic incidence of embryonic loss in successive litters, imposed by factors which must be either inherited or else acquired before puberty. These alternatives are discussed with reference to the available data.
\end{abstract}

\section{INTRODUCTION}

The results to be described were obtained from two series of observations in which prenatal mortality was measured by counting the corpora lutea of pregnancy at laparotomy and using this figure as the equivalent of the ovulation rate for comparison with the number of young at parturition. The first part of the work was carried out on pigs which formed part of a well-established pedigree herd, but no selection or breeding plan was imposed beyond what was involved in the normal practice of the farm. The results led to the conclusion that the daughters of different boars tended to experience a characteristic incidence of embryonic loss during pregnancy, irrespective of either their dams or, as far as the data showed, the boars with which they were mated. For the second part of the work, done at Babraham, two groups of females were 
selected, and mated, in such a way that differences in average embryonic mortality could be analysed with reference to the mother's sire, dam and mate.

\section{METHODS AND RESULTS}

\section{EMBRYONIG MORTALITY IN GILTS}

This part of the investigation was carried out at Compton, using animals from the Agricultural Research Council's herd of pedigree Large White pigs, in which the level of inbreeding was very low. The original aim was to measure embryonic loss in successive pregnancies in a group of individuals which were not selected except as being representative of the herd of which they formed a part. The surgical procedure which was used, however, was found to affect the animal's reproductive function subsequent to the pregnancy during which it was carried out, although there was no reason to suppose that it affected the course of the current pregnancy. The data discussed below, therefore, relate to the first pregnancy only. The ovaries of each gilt were examined, usually at some time in the second month of pregnancy, by means of a right flank laparotomy under Nembutal and ether anaesthesia. It was possible to count the corpora lutea in both ovaries and this count was used as the equivalent of the ovulation rate. The error involved in this assumption appears to be small; its magnitude is the subject of a separate study still in progress.

\section{Embryonic Loss in Relation to Ovulation Rate}

The number of corpora lutea, and the number of young born, are shown in Table I, where the animals are listed in order of the number of corpora lutea. The percentage of ova 'lost' has been calculated both as the discrepancy between the number of corpora lutea and of $(a)$ young born alive and $(b)$ the total number of young identifiable at parturition. The former figure serves as a measure of the loss in potential productivity but the latter figure, where stillbirths are not counted among those 'lost', is more appropriate to the comparison of embryonic mortality in different groups of animals, since it is clear that the distribution, and presumably therefore the cause, of stillbirths in pigs is widely different from that of earlier prenatal mortality. The distribution of stillbirths in relation to litter size has been described by Krizenecky (I935), Podhradsky (1937) and Perry (1956). It has been shown that about three-quarters of the embryonic mortality in a typical pig population occurs between ovulation and the $25^{\text {th }}$ day of pregnancy (Squiers, Dickerson \& Mayer, 1952; Perry, I 954) and the greater part of this early loss appears to be due to failure in nidation. In the present work, however, it was not found practicable to count surviving embryos during pregnancy, so that the available data include as 'lost' all the ova which were presumed to have left the ovary but were not accounted for at parturition.

The ovulation rate was relatively limited in range compared with what is general for this species, but this is accounted for by the fact that the animals were nulliparous females (Perry, 1954). There is one exceptional animal which had thirty-three corpora lutea, all of which appeared normal and functional. 
Table I shows that there was no correlation between the number of corpora lutea and the percentage of ova lost among animals with eleven to eighteen

TABLE I

CORPORA LUTEA OF PREGNANGY, AND PIGLETS BORN, IN THIRTY-SIX LARGE WHITE PIGS IN FIRST PREGNANCY

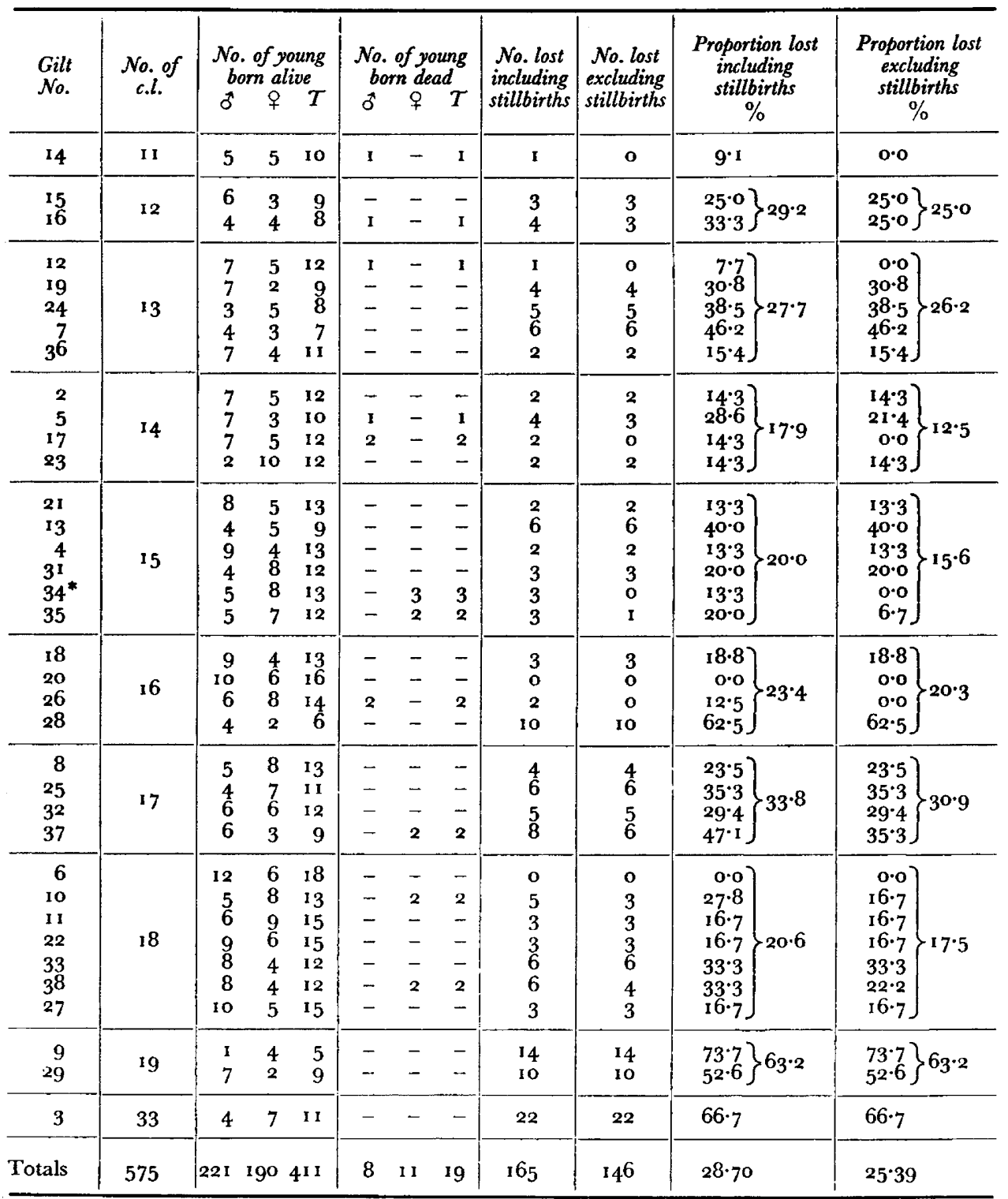

* Total number of young born exceeded c.l. count by one.

corpora lutea. It is impossible to draw any conclusion as to the possible significance of the heavy embryonic mortality among the remaining three animals, but it is evident that these data do not illustrate a linear regression of percentage 


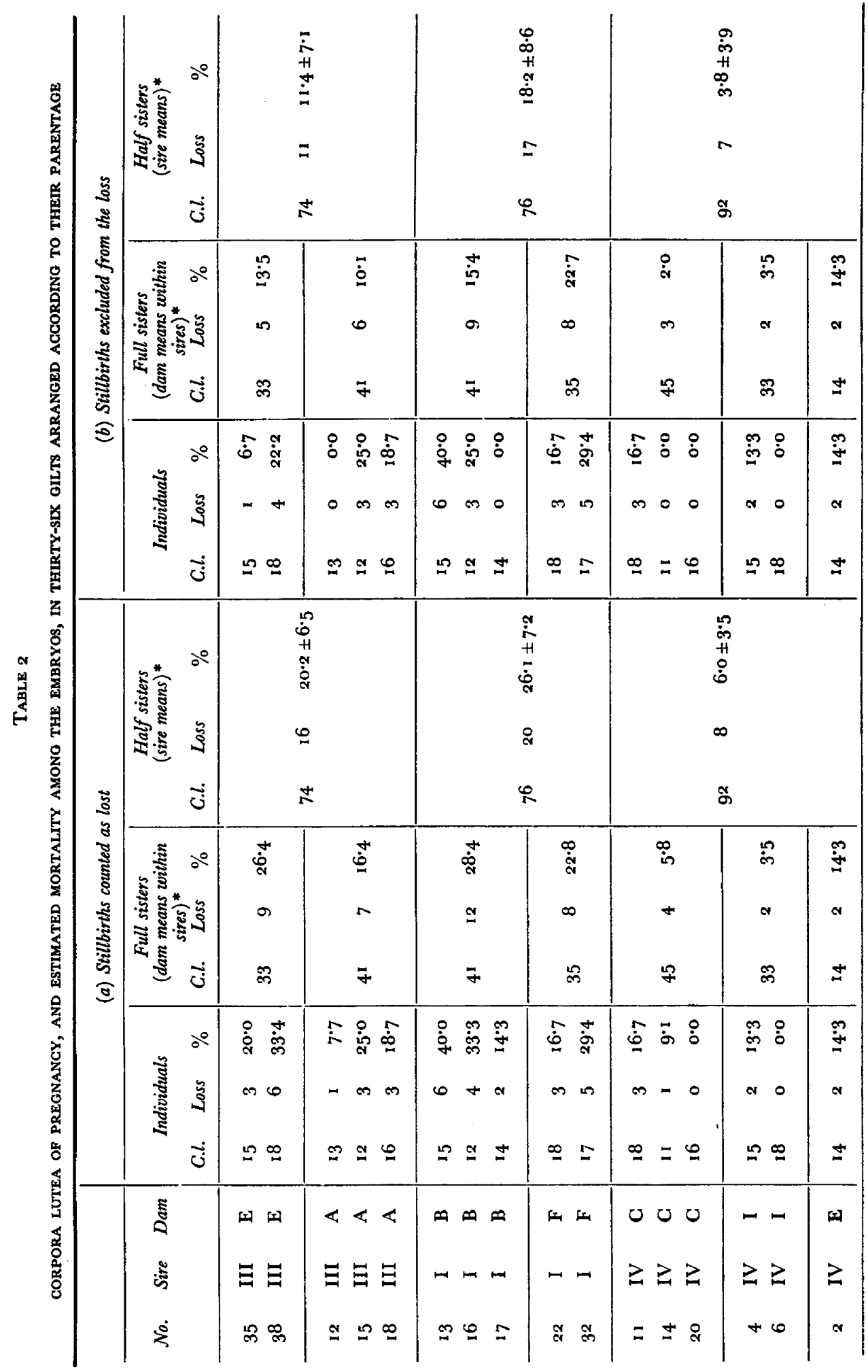


Embryonic Mortality in Sows

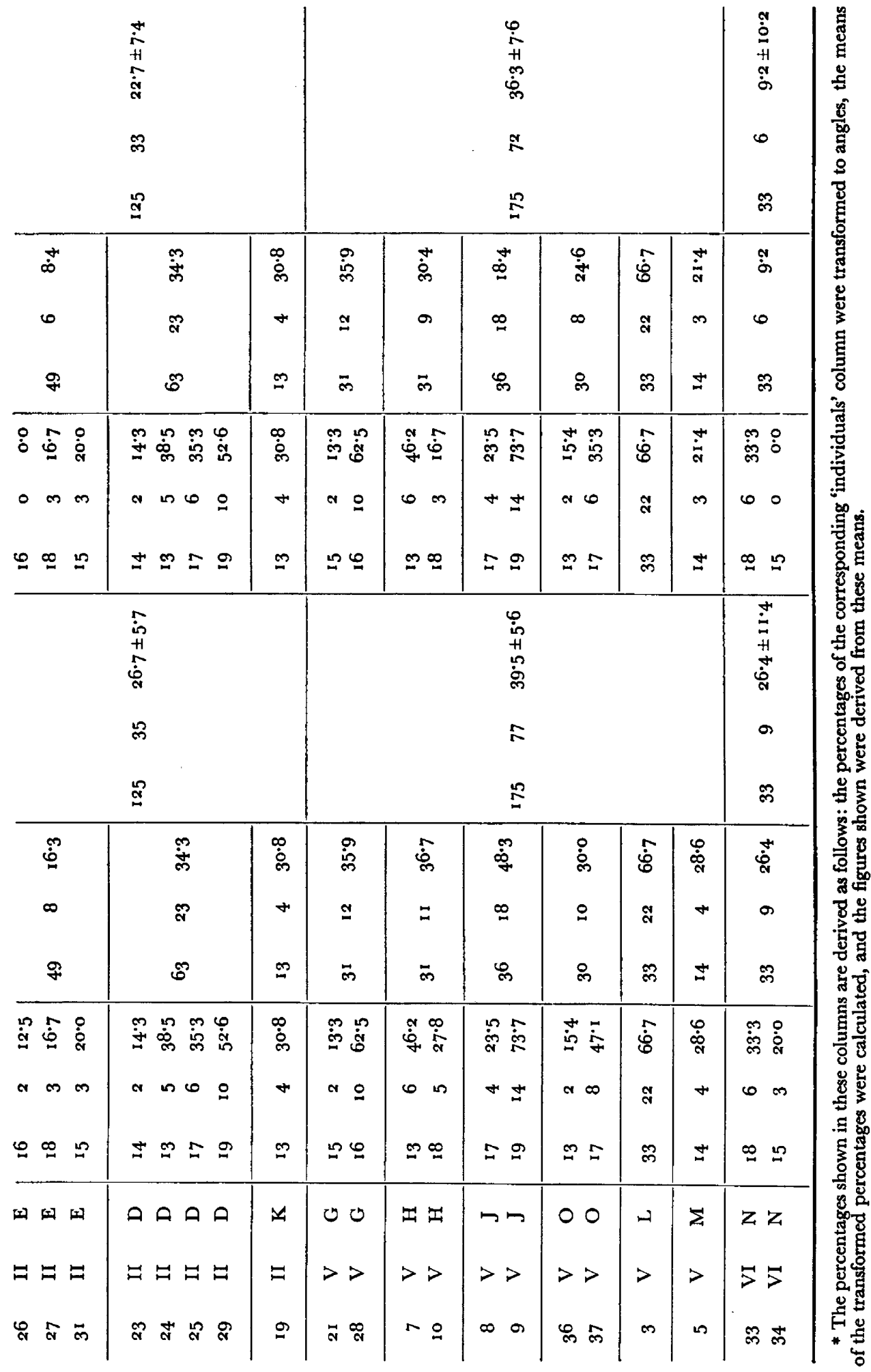


mortality on the ovulation rate, such as has been described in some pig populations. The sex ratio among the 430 young born alive was $53 \cdot 26 \pm 2 \cdot 4 \%$ males, and there was no significant difference between the numbers of males and females born dead.

In one case the number of corpora lutea counted was one less than the total number of young born. Subsequent experience has shown that a corpus luteum may become hidden from view within the ovary as pregnancy proceeds, at least in some multiparous animals. This is less common in the first pregnancy but it may explain the miscount in this case. A miscount of corpora lutea by superficial examination, as revealed by dissection of the ovary, is found to be almost invariably one less than the actual number.

\section{Inherited Factors in Embryonic Mortality}

These thirty-six gilts were next grouped in accordance with their immediate pedigree and breeding history in order to relate the observed percentage mortality to the individual's sire, dam and mate. The animals were among the progeny of fourteen dams and six sires, and they were distributed for service among six boars. Because no particular breeding plan was involved in the original project (see above), it is not possible completely to segregate these different factors. In fact, the gilts mated to a particular boar usually comprised one or more groups of litter sisters, so that groups of gilts mated to the same boar were statistically inextricable from groups which were members of the same litter. The possible influence of the 'mates' has therefore been ignored in this analysis. In subsequent work, described below, it was found that embryonic loss was independent of the identity of the 'mate'. The animals can be arranged hierarchically as full sisters (members of the same litter) and half sisters (sharing the sire but not the dam). This is done in Table 2. As there was only one animal (L 2) which shared the dam of one of the groups of litter sisters without also sharing the sire, the grouping according to sires is almost the same as grouping according to the sharing of one parent but not both. Thus, as it happened, all the full sisters were litter sisters and, with one exception, all the half sisters were paternal half sisters. The data are again presented with and without the inclusion of stillbirths.

The significance tests designed to discriminate between the influence of sires and dams were carried out on the percentages shown in the 'Individuals' columns of Table 2. These were transformed to angles, and the transformed percentages were analysed unweighted. The mean square for 'dams within sires' was found not to differ significantly from that for 'individuals within dams'. These two mean squares were therefore pooled to provide the error term for testing the significance of sire differences and for calculation of standard errors. The actual mean squares were as follows:

Between sires

Between dams within sires

Between individuals within dams

$\begin{array}{rcc}\text { d.f. } & \begin{array}{c}\text { Stillbirths } \\ \text { counted } \\ \text { as lost }\end{array} & \begin{array}{c}\text { Stillbirths } \\ \text { excluded } \\ \text { from the loss }\end{array} \\ 5 & 472 \cdot 5 & 58 \mathrm{1} \cdot 2 \\ 11 & 77^{\circ} & 134 \cdot 5 \\ 19 & 127 \cdot 9 & 245 \cdot 2\end{array}$


The differences between 'sire means' are statistically significant $(P<0 \cdot 0$ I when stillbirths are included in the loss; $P<0.05$ when they are excluded). The differences between 'dam means' within sires are not significant. The data thus provide strong evidence for differences associated with the sires of the breeding females, and as all the animals were members of a single herd this must be regarded as presumptive evidence that the differences are genetic. The calculation was duplicated for the data excluding the animal $L_{3}$, with thirty-three corpora lutea, but this did not affect the conclusion. Thus it appears that the heterogeneity of these data in respect of the proportion of embryos lost, is attributable to the paternal parentage of the females.

\section{EMBRYONIC MORTALITY IN THE FIRST TWO PREGNANGIES OF PIGS}

This work was undertaken at Babraham and a surgical technique was developed there which appears to overcome the difficulties encountered in the earlier work, when many of the animals developed adhesions between the ovaries and the oviducal fimbria. Such adhesions must presumably prejudice normal ovum transport in subsequent pregnancies although they do not affect the current pregnancy. They appear to have been caused by the intraperitoneal application of sulphonamide in a powder form, and they have not occurred since this practice was abandoned. An account of the anaesthetic technique, involving the use of cyclopropane, has been published elsewhere (Hill \& Perry, 1959). By these means, it has been possible to count the corpora lutea of pregnancy in more than one gestation in the same animals.

In order to discriminate between the effects of mates as well as dams and sires, sixteen pedigree Large White pigs were selected from the progeny of two sires and four dams, as follows:
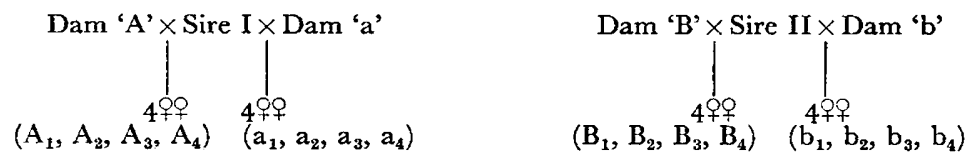

Two boars of suitable age for mating with these sixteen females were also chosen; they are referred to below as the 'mates', $\mathrm{X}$ and $\mathrm{Y}$. The four dams, the two sires and the two mates were all unrelated to each other within four generations and shared practically no common ancestry as far as could be traced. No selection was employed other than the rejection of any source which did not comply with this condition, and the choice may be regarded as bein? random. The pedigrees were checked by means of the relevant volumes of the herd books of the National Pig Breeders Association.

The first litters were produced by mating the eight daughters of Sire I with Boar X, and those of Sire II with Boar Y. The second litters were by matin 3 the daughters of Sire I with Boar Y and those of Sire II with Boar X. The corpora lutea were counted by laparotomy early in pregnancy and the piglets were counted at parturition as in the previous work. The results are shown in Table 3, where the 'survivors' represent all identifiable piglets born, alive or dead, and 
the 'loss' is the discrepancy between the number of corpora lutea and the number of survivors. Stillbirths are excluded from the 'loss' for the reasons discussed above.

TABLE 3

CORPORA LUTEA OF PREGNANCY, FOETUSES SURVIVING TO TERM, AND ESTIMATED EMBRYONIC LOSS IN SIXTEEN PIGS

\begin{tabular}{|c|c|c|c|c|c|}
\hline & $\begin{array}{c}\text { Full-sister } \\
\text { groups }\end{array}$ & $\begin{array}{c}\text { Corpora } \\
\text { lutea }\end{array}$ & Survivors & Loss & $\%$ \\
\hline First litter & $\begin{array}{l}A_{1}-A_{4} \\
a_{1}-a_{4} \\
B_{1}-B_{4} \\
b_{1}-b_{4}\end{array}$ & $\begin{array}{l}60 \\
49 \\
51 \\
54\end{array}$ & $\begin{array}{l}37 \\
35 \\
42 \\
44\end{array}$ & $\begin{array}{r}23 \\
14 \\
9 \\
10\end{array}$ & $\begin{array}{l}38 \cdot 33 \\
28 \cdot 57 \\
17 \cdot 65 \\
18 \cdot 52\end{array}$ \\
\hline Second litter & $\begin{array}{l}A_{1}-A_{4} \\
a_{1}-a_{4} \\
B_{1}-B_{4} \\
b_{1}-b_{4}\end{array}$ & $\begin{array}{l}66 \\
60 \\
61 \\
63\end{array}$ & $\begin{array}{l}45 \\
31 \\
53 \\
50\end{array}$ & $\begin{array}{r}21 \\
29 \\
8 \\
13\end{array}$ & $\begin{array}{l}31 \cdot 82 \\
48 \cdot 33 \\
13 \cdot 11 \\
20 \cdot 63\end{array}$ \\
\hline
\end{tabular}

Embryonic mortality was distributed similarly in the first and second pregnancies, and the percentage loss was not significantly different whether the female was mated with Boar X or Boar Y. The loss is therefore independent of the boar to which the mother was mated, and the average percentage loss

TABLE 4

PERCENTAGE LOSS OF OVA IN THE FIRST TWO LITTERS OF EACH OF SIXTEEN PIGS

\begin{tabular}{|c|c|c|c|c|c|}
\hline \multirow{2}{*}{ Sire } & \multirow{2}{*}{ Dam } & \multirow{2}{*}{$\begin{array}{c}\text { Experimental } \\
\text { animals }\end{array}$} & \multicolumn{3}{|c|}{ Average loss (\%) } \\
\hline & & & Individuals & Dam means* & Sire means* \\
\hline \multirow{2}{*}{ I } & 'A' & $\begin{array}{l}A_{1} \\
A_{2} \\
A_{3} \\
A_{4}\end{array}$ & $\begin{array}{r}27 \cdot 4 \\
16 \cdot 4 \\
72 \cdot 6 \\
7 \cdot 7\end{array}$ & $28 \cdot 9$ & \multirow{2}{*}{$34 \cdot I \pm 5 \cdot 8$} \\
\hline & ' $a$ ' & $\begin{array}{l}a_{1} \\
a_{2} \\
a_{3} \\
a_{4}\end{array}$ & $\begin{array}{l}29^{\circ} 0 \\
31.0 \\
53^{\circ} 0 \\
4^{\circ} \cdot 0\end{array}$ & $39^{\cdot 6}$ & \\
\hline \multirow{2}{*}{ II } & 'B' & $\begin{array}{l}\mathrm{B}_{1} \\
\mathrm{~B}_{2} \\
\mathrm{~B}_{3} \\
\mathrm{~B}_{4}\end{array}$ & $\begin{array}{l}13 \cdot 1 \\
10 \cdot 6 \\
20 \cdot 9 \\
14 \cdot 2\end{array}$ & $14: 5$ & \multirow{2}{*}{$15 \cdot 6 \pm 3 \cdot 2$} \\
\hline & 'b' & $\begin{array}{l}b_{1} \\
b_{2} \\
b_{3} \\
b_{4}\end{array}$ & $\begin{array}{r}22 \cdot 6 \\
1 \cdot 8 \\
16 \cdot 0 \\
35 \cdot 5\end{array}$ & $16 \cdot 6$ & \\
\hline
\end{tabular}

* See note at foot of Table 2.

among individuals, among the daughters of the Dams A, a, B and b (full-sister groups, or dam means), and among the daughters of the Sires I and II (halfsister groups, or sire means), can be calculated for both pregnancies together, as in Table 4 . The sire means differed significantly $\left(P<0^{\cdot 05}\right)$; the dam means 
did not differ significantly within sires. The results therefore confirm the conclusion drawn from the data relating to thirty-six gilts of the Compton herd (above), that the percentage loss depends on the sire of the sow, but not on the dam or the mate of the sow.

\section{Subsequent History of the Sixteen Sows}

The above analysis is confined to the first two pregnancies because some confusion between sires and mates was later introduced. However, as the

TABLE 5

CORPORA LUTEA OF PREGNANCY AND NUMBER OF YOUNG BORN IN FIFTY LITTERS FROM SIXTEEN PIGS

\begin{tabular}{|c|c|c|c|c|c|c|c|c|c|}
\hline \multicolumn{5}{|c|}{ Daughters of Sire I } & \multicolumn{5}{|c|}{ Daughters of Sire II } \\
\hline No. & C.l. & Born & Lost & $\%$ loss & No. & C.l. & Born & Lost & $\%$ loss \\
\hline \multirow{3}{*}{$\begin{array}{c}\mathbf{A}_{1} \\
" \\
,\end{array}$} & 21 & 9 & 12 & $57 \cdot 14$ & $\mathbf{B}_{1}$ & 12 & I I & I & $8 \cdot 33$ \\
\hline & 17 & I 6 & 1 & 5.88 & , & 16 & 13 & 3 & $18 \cdot 75$ \\
\hline & 22 & 13 & 9 & $40 \cdot 91$ &, & 21 & 14 & 7 & $33 \cdot 33$ \\
\hline \multirow{2}{*}{$\begin{array}{l}\ddot{A}_{2} \\
, \dddot{m}\end{array}$} & 14 & 13 & I & $7 \cdot 14$ & $\mathbf{B}_{2}$ & 13 & II & 2 & 15.38 \\
\hline & 14 & I0 & 4 & $28 \cdot 57$ & $"$ & 15 & 14 & I & 6.67 \\
\hline $\mathrm{A}_{3}$ & 14 & 2 & 12 & 85.71 & $"$ & 20 & 12 & 8 & $40 \cdot 00$ \\
\hline \multirow{2}{*}{ ", } & 21 & 9 & 12 & $57^{\circ} 14$ & $\mathrm{~B}_{3}$ & 13 & 10 & 3 & $23 \cdot 08$ \\
\hline & I 8 & 14 & 4 & $22 \cdot 22$ & , & 16 & I3 & 3 & I $8 \cdot 75$ \\
\hline \multirow{2}{*}{ Ä } & 24 & 10 & 14 & $5^{8 \cdot 33}$ & ", & 20 & 16 & 4 & $20 \cdot 00$ \\
\hline & 11 & 13 & o & 0.0 & $\mathrm{~B}_{4}$ & 13 & 10 & 3 & 23.08 \\
\hline \multirow{2}{*}{$"$} & 14 & 10 & 4 & $28 \cdot 57$ & ", & 14 & 13 & I & $7 \cdot 14$ \\
\hline & 17 & 14 & 3 & 17.65 & " & 15 & 12 & 3 & $20 \cdot 00$ \\
\hline$a_{1}$ & 11 & 9 & 2 & $18 \cdot 18$ & $b_{1}$ & I 5 & 11 & 4 & $26 \cdot 67$ \\
\hline \multirow{2}{*}{ ", } & 17 & 10 & 7 & $4^{I} \cdot 18$ & , & I & 13 & 3 & $18 \cdot 75$ \\
\hline & 17 & 9 & 8 & $47^{\circ} .06$ & ", & I 6 & 12 & 4 & $25^{\circ} 00$ \\
\hline \multirow{2}{*}{$\mathbf{a}_{2}$} & 13 & 9 & 4 & 30.77 & ", & I 5 & II & 4 & $26 \cdot 67$ \\
\hline & $1 \overrightarrow{6}$ & I I & 5 & $31 \cdot 25$ & $b_{2}$ & IO & I I & 0 & 0.0 \\
\hline \multirow{2}{*}{$a_{3}$} & 15 & 9 & 6 & $40 \cdot 00$ & ", & 14 & 13 & I & $7 \cdot 14$ \\
\hline & 14 & II & 3 & $21 \cdot 43$ & ", & I8 & 15 & 3 & 16.67 \\
\hline \multirow{2}{*}{ ", } & 12 & 2 & I0 & $83 \cdot 33$ & ", & 17 & 10 & 7 & $41 \cdot 18$ \\
\hline & 18 & 9 & 9 & $50 \cdot 00$ & $b_{3}$ & 13 & I I & 2 & $15.3^{8}$ \\
\hline \multirow[t]{3}{*}{$a_{4}$} & I I & 6 & 5 & 45.45 & " & $1 \breve{8}$ & 15 & 3 & 16.67 \\
\hline & 15 & 8 & 7 & $46 \cdot 67$ & ", & 20 & 14 & $\breve{6}$ & $30 \cdot 00$ \\
\hline & 18 & 10 & 8 & $44 \cdot 44$ & $"$ & 25 & I I & 14 & $56 \cdot 00$ \\
\hline \multirow{2}{*}{$"$} & & & & & $b_{4}$ & $1 \breve{6}$ & I I & 5 & $31 \cdot 25$ \\
\hline & & & & & ", & I 5 & 9 & 6 & $40 \cdot 00$ \\
\hline $\begin{array}{l}\text { Totals } \\
\text { Averages* }\end{array}$ & $\begin{array}{l}3^{84} \\
16 \cdot 00\end{array}$ & $\begin{array}{l}236 \\
9^{-83}\end{array}$ & $\begin{array}{l}150 \\
6 \cdot 25\end{array}$ & $3^{8 \cdot 54 \pm 4 \cdot 31}$ & $\begin{array}{l}\text { Totals } \\
\text { Averages* }\end{array}$ & $\begin{array}{l}416 \\
16 \cdot 0\end{array}$ & $\begin{array}{l}316 \\
12 \cdot 15\end{array}$ & $\begin{array}{l}\text { IOI } \\
\quad 3.9\end{array}$ & $24.04 \pm 2.47$ \\
\hline
\end{tabular}

* Some discrepancy introduced by one animal in each group with excess of young over c.l. count.

influence of the mate has been shown to be insignificant it may be ignored in further comparison of the two groups of half sisters, which have always been mated with one or other of the two boars $\mathrm{X}$ and $\mathrm{Y}$.

The corpora lutea of pregnancy have been counted in a total of fifty pregnancies in these sixteen animals to date. Two of the sows have been killed for reasons unconnected with their reproductive function, and fourteen survive at the time of writing. The series of laparotomies was temporarily discontinued after some of the sows had been examined in four successive pregnancies. A bony callus formed in the body-wall at the site of the midline incision in some animals, and it was thought that a number of laparotomies repeated at relatively 
short intervals might dangerously weaken the body-wall. No internal adhesions have been encountered and the surviving animals are still breeding regularly. It is intended to perform a series of laparotomies at a much later stage of the life-cycle of these individuals, both to determine whether the two groups maintain the different levels of embryonic mortality and to study the effect of age on embryonic mortality within the individual sow.

The fifty pregnancies for which corpus luteum counts are available are listed in Table 5. It will be seen that the characteristically high percentage loss among the daughters of Sire $I$ is maintained so far. The sire means for the twenty-four litters derived from Sire I and the twenty-six derived from Sire II are respectively $38.54 \pm 4.31 \%$ and $24 \pm 2.47 \%$. It has been shown elsewhere (Perry, I959) that the percentage of embryonic loss among the daughters of Sire II was linearly related to the number of corpora lutea, whereas this was not true of the daughters of Sire I. It has been suggested that the fraction of embryonic loss which is related to litter size is common to both groups, while the daughters of Sire I experience further embryonic mortality which is not so related and which is presumably due to a different cause.

The average number of young born to daughters of Sire I was 9.83 compared with an average of $12 \cdot 15$ young born to daughters of Sire II. The difference is accounted for entirely by the difference in embryonic mortality, for the average number of corpora lutea of pregnancy was 16 in both groups. Since the discontinuation of routine laparotomies, the daughters of Sire I have borne a further nine litters, with an average of $10 \cdot 0$ young, and the daughters of Sire II have borne eleven litters with an average of $12 \cdot 3$ young. The continuing difference in the birth rate suggests that the difference in embryonic mortality is being maintained.

\section{DISCUSSION}

It is clear that the distribution of prenatal mortality among members of a sample pig population is likely to fall into a pattern which is in some way determined by factors which operate before the mothers reach puberty and exert an effect which persists beyond the first two litters. Among the animals for which data are available, the incidence of prenatal mortality is significantly related to the immediate pedigree, in that there are significant differences between groups of half sisters when the common parent of the group is the sire. The conclusion that the mortality among embryos is genetically controlled and is dependent on the mother's sire (the grandsire of the embryo) does not easily accord with what is known of the inheritance of factors affecting fertility, and possible alternative explanations must be considered.

The first part of this investigation (the Compton series) was not specifically designed to examine the relation of prenatal mortality to pedigree. No alternative arrangement of the data has been found, however, which explains the nonrandom nature of the distribution. By the time further investigation was planned, the original sires were no longer available for study, and the Compton herd had been drastically altered, so that it was necessary to use animals from elsewhere. The plan of selecting daughters of pairs of unrelated dams, both of which had 
been served by the same boar, provided a simple means of distinguishing between effects due to sires, dams and mates. No single herd was located which could furnish more than one such group of half sisters. Each group was therefore taken from a different farm, and each was therefore subject to environmental influences presumably characteristic of the farm, up to the time of purchase and transfer to Babraham, shortly before puberty.

If the two groups of half sisters in the Babraham series are compared as in Table 5 , the results, taken by themselves, are more readily comprehensible as a manifestation of persistent effects of early environment than as a result of heredity. The reason lies, not in there being any positive evidence in favour of an 'environmental' interpretation, but in the difficulties of the alternative genetic explanation. In the first place, the heritability of litter size is known to be low, approximating to a value of 0.2 (see Squier, Dickerson \& Mayer, 1952). The term 'heritability' is applied to situations where genotypic influence on a character is of a complex sort, as in the case of litter size in normal polytocous mammals, but not to the effect which, for instance, a single lethal gene might have on litter size. It represents the heritable portion of the variance observed in a given characteristic, expressed as a fraction of the total variance, and a difference ' $x$ ' in the value of a particular phenotype recorded from two populations implies a difference of $x / h$, where ' $h$ ' is the heritability factor, in the genotypic constitution of the two populations. It can be seen from Table 5 that the average litter size at birth in the Babraham series was 9.83 in one group of half sisters and $12 \cdot 15$ in the other. Such a difference, if it is maintained by differences of genotype in the sires alone, with a heritability factor of 0.2 , implies an enormous genotypic difference between the sires, which would be most unlikely to persist in the population in general.

Environmental factors, on the other hand, can be comparatively easily imagined to cause permanent effects leading to such results in this series of animals. This explanation, however, is less readily acceptable in the case of the Compton series, where the investigation was conducted entirely within a single herd, especially as the variation between full-sister groups within half-sister groups was not significant. It would be thought, a priori, that 'environmental factors common to litters' would constitute a major component of such variation if it were in fact shown to exist within a single herd. The recurrence of high percentage loss among the embryos of the daughters of Sire I in the Babraham series implies a degree of 'repeatability' in successive litters which is significant whether the cause is inherited or environmental.

The significant difference between 'sire means' with no significant differences between 'dam means' within sires (Tables 3 and 4 ) in the Babraham series, could well be due to chance selection of one pair of dams of a 'high mortality' and one of a 'low mortality' strain, with no real difference between the sires. Like the hypothesis that the difference is of environmental origin, this interpretation would not apply to the Compton series.

A type of genetic mechanism which could conceivably account for a distribution of the kind described is one in which the inheritance of a character is controlled by a relatively simple gene complex, or by a single dominant gene, which only becomes effective in particular circumstances, so that the genotype 
may be widespread in the population whereas the phenotype only occurs sporadically.

Reddy, Lasley \& Mayer (1958) showed that the ovulation rate in a group of crossbred gilts was significantly related to the 'sires of the families' (i.e. to the 'sire' as the term is used in this account) and less than significantly to the dams. Prenatal mortality did not appear to be related to the identity of the sire until the means were adjusted to allow for differences in the age of the gilts, and in the ovulation rate. When this was done it was shown that 'the sires of the families were a major contributing source of variation $(P<0.025)$. The differences among dams approached significance when the mean embryonic mortality was adjusted for variation in the ovulation rate'. The authors concluded that a boar of normal fertility does not influence the reproductive performance of the females mated with him, but does pass on genetic traits affecting the fertility of his daughters and the proportion of their embryos which will survive the first half of pregnancy. They emphasized the importance of embryonic mortality in determining litter size, but they did not discuss the implications of their results in relation to the heritability of litter size.

The differences in prenatal mortality among the half-sister groups described above, and shown in Tables 2 to 5 , can be seen to be due, in the main, to differences affecting the generality of individuals rather than the occurrence of a few exceptional individuals with a very high or very low mortality in particular groups. Table 5, with 2 to 4 litters from each animal, shows that the average mortality among embryos of individual mothers was consistently higher among daughters of Sire I. Nevertheless, great variation sometimes exists between successive litters in the same individuals. This variation does not appear to bear any relation to the identity of the 'mates' (boars X and Y) or to the sequence of mating - e.g. no effect has been detected that could be attributed to service by $\mathrm{X}$ following previous service by $\mathrm{Y}$, or any other combination of this sort.

It can be seen from Table 5 that an exceptionally high proportion of embryos was lost in two of the litters derived from Sire I, but the omission of these two litters does not greatly reduce the average mortality within the group as a whole, and if all 'losses' of more than $50 \%$ are omitted from both groups, the substantial difference between the respective sire means is maintained. The variation in actual numbers of embryos 'lost' among the twenty-four litters related to Sire $\mathbf{I}$ is very similar to that among the twenty-six related to Sire II, and the variance ratio, F, between the two groups is not significantly high. There is, however, greater variation in the percentage 'lost' among the daughters of Sire I than among the daughters of Sire II, and the variance ratio $(F=2 \cdot 83)$ is greater than the value entered for the appropriate number of degrees of freedom in Snedecor's table.

Both the average and the range of the number of corpora lutea are very similar in the two half-sister groups of the Babraham series, and the range is restricted as compared with that found in a random sample of pigs of various breeds and crosses (Perry, I954). The proportion of ova 'lost' is apparently related to the number ovulated in the twenty-six litters derived from Sire II. The relation appears to be linear and the coefficient of correlation is about $0 \cdot 7$ 
(Perry, 1959). There is no similar correlation between these two variables in the twenty-four litters derived from Sire I. It is possible that a certain percentage mortality is common to both groups, while a further loss, which is not in proportion to the numbers ovulated, is superimposed on this basic loss in one of them. The Compton data, however, suggest that divergence from the usual may tend to a lower percentage loss in some groups, as well as to a higher percentage in others.

\section{ACKNOWLEDGMENTS}

It is a pleasure to acknowledge the collaboration of $\mathrm{Mr} \mathrm{K}$. J. Hill, of this Institute, in the development of surgical methods suitable for work on large pigs, and the technical assistance of Mr P. N. O'Donoghue throughout the course of this investigation. I am particularly indebted to Mr J. G. Rowell, of the A.R.C. Statistics Unit, Cambridge, who designed and carried out the main statistical analyses which have been quoted in this account, and to $\mathrm{Dr} \mathrm{R}$. A. Beatty, of the Institute of Animal Genetics, Edinburgh, who read the manuscript.

\section{REFERENCES}

Hill, K. J. \& Perry, J. S. (1959) A method of closed-circuit anaesthesia in the pig. Vet. Rec. 71, 296. Krizenecky, J. (1935) The number of stillborn pigs in relation to litter size. Ann. Acad. tchécosl. Agric. IO, 222.

Perry, J. S. (1954) Fecundity and embryonic mortality in pigs. 7. Embryol. exp. Morph. 2, 308.

Perry, J. S. (1956) Observations on reproduction in a pedigree herd of Large White pigs. 7 . agric. Sci. 47, 332.

Perry, J. S. (1959) The number of ova ovulated and the proportion of embryonic mortality in the pig. Int. J. Fertil. 4, 142.

Podmradsky, J. (1937) The influence of litter size on death of the pigs at birth. Ann. Acad. tchécosl. Agric. 12, 509 .

Reddy, V. B., LAsley, J. F. \& MaYer, D. T. (1958) Genetic aspects of reproduction in swine. Res. Bull. Mo. agric. Exp. Sta., No. 666.

Squiers, C. D., Dickerson, G. E. \& Mayer, D. T. (1952) Influence of inbreeding, age and growth rate of sows on sexual maturity, rate of ovulation, fertilization and embryonic survival. Res. Bull. Mo. agric. Exp. Sta. No. 494 , p. $4^{\circ}$. 